\title{
Upregulation of stromal cell-derived factor $1 \alpha$ expression is associated with the resistance to neoadjuvant chemoradiotherapy of locally advanced rectal cancer: Angiogenic markers of neoadjuvant chemoradiation
}

\author{
HAN JO KIM ${ }^{1}$, SANG BYUNG BAE ${ }^{1}$, DONGJUN JEONG ${ }^{2}$, EUN SEOG KIM ${ }^{3}$, CHANG-NAM KIM ${ }^{4}$, \\ DONG-GUK PARK ${ }^{5}$, TAE SUNG AHN ${ }^{6}$, SUNG WOO CHO ${ }^{6}$, EUNG JIN SHIN ${ }^{6}$, \\ MOON SOO LEE ${ }^{6}$ and MOO JUN BAEK ${ }^{6}$ \\ Departments of ${ }^{1}$ Internal Medicine, ${ }^{2}$ Pathology and ${ }^{3}$ Radiation Oncology, Soonchunhayng University \\ College of Medicine, Cheonan; ${ }^{4}$ Department of Surgery, Eulji University College of Medicine, Daejeon; \\ ${ }^{5}$ Department of Surgery, Dankook University College of Medicine, Cheonan; ${ }^{6}$ Department of Surgery, \\ Soonchunhayng University College of Medicine, Cheonan, Republic of Korea
}

Received July 25, 2014; Accepted September 5, 2014

DOI: $10.3892 / o r .2014 .3504$

\begin{abstract}
The ability to achieve pathologic downstaging after neoadjuvant chemoradiotherapy (NCRT) is correlated with improved survival in locally advanced rectal cancer (LARC). However, there is no effective predictive markers. In this study, the expression of angiogenic markers was evaluated in pretreatment biopsies and corresponding post-treatment resection specimens, and were correlated to histopathological tumour characteristics and response. Fifty-five patients with stage II/III rectal cancer treated with 5-fluorouracil (5-FU)-based NCRT were studied. All patients were administered NCRT followed by surgical resection. Immunohistochemical staining for angiogenic markers [hypoxia-inducible factor $1 \alpha$ (HIF-1 $\alpha$ ), vascular endothelial growth factor (VEGF), stromal cell-derived factor $1 \alpha$ (SDF-1 $\alpha)$ and placental growth factor (PlGF)] was performed on specimens obtained before NCRT and after surgery. Expression of VEGF, PlGF and HIF-1 $\alpha$ protein was downregulated after NCRT in the rectal cancer tissues $(\mathrm{P}<0.001, \mathrm{P}=0.001$ and $\mathrm{P}=0.044$, respectively). However, SDF-1 $\alpha$ was upregulated after NCRT $(\mathrm{P}<0.001)$ Moreover, upregulated expression of SDF-1 $\alpha(\mathrm{P}=0.016)$ and positive PlGF staining $(\mathrm{P}=0.001)$ after NCRT were significantly associated with resistance to NCRT. On multivariate analysis, positive PIGF staining after NCRT was found to be independently associated with resistance to NCRT $(\mathrm{P}=0.013)$.
\end{abstract}

Correspondence to: Professor Moo Jun Baek, Department of Surgery, Soonchunhayng University College of Medicine, 23-20 Byeongmyeong-Dong, Dongnam-Gu, Cheonan-Si, Chungcheongnam-Do 330-721, Republic of Korea

E-mail: ssurge@sch.ac.kr

Key words: neoadjuvant chemoradiotherapy, stromal cell-derived factor $1 \alpha$, treatment prediction, rectal cancer
Our data suggest that SDF-1 $\alpha$ and PIGF should be evaluated as new targets for NCRT in LARC.

\section{Introduction}

Rectal cancer (RC) is a major health issue and is one of the leading causes of cancer-related death worldwide (1). Neoadjuvant chemoradiotherapy (NCRT) followed by surgical resection is the current standard treatment for locally advanced rectal cancer (LARC). It offers improved local control, reduced toxicity and higher rates of sphincter preservation without compromising oncological outcome compared with post-operative treatment $(2,3)$. A pathologic complete response (pCR) is one of the best predictive markers of a favourable prognosis. However, approximately $15-30 \%$ of patients experience a pCR, whereas the majority of patients have some degree of residual disease after NCRT (4). Thus, if patients with tumours that are responsive to NCRT could be identified at the time of diagnosis, then NCRT could be administered in a more individualised manner.

Recent studies have attempted to identify predictive biomarkers such as Ki-67, p53, p21, p27, bax, BCL-2, vascular endothelial growth factor (VEGF), epidermal growth factor receptor (EGFR), survivin and thymidylate synthase $(5,6)$. However, clinical use of these biomarkers requires further evaluation in prospective clinical trials (7).

Angiogenesis is necessary for tumour growth and malignant progression, with VEGF being a key angiogenic factor. High VEGF expression was found to be associated with poor survival in colorectal cancers (8). In particular, bevacizumab, a humanised monoclonal antibody inhibiting VEGF-A, in combination with standard chemotherapy regimens was beneficial both in terms of response rate and survival as firstand second-line treatment of patients affected by metastatic colorectal cancer. In patients affected by LARC who underwent radical surgery and adjuvant chemoradiation, tumour 
VEGF overexpression was found to be associated with a statistically higher risk of local recurrence and metastasis (9). Not only VEGF, but placental growth factor (PIGF) are potentially useful predictive factors in rectal cancer (10).

Hypoxia is one of the key stimuli for the release of angiogenic markers (AMs) necessary for angiogenesis and tumour growth. Hypoxic tumours not only have a more aggressive nature $(11,12)$, but studies in cervical and head and neck cancer demonstrated that tumour hypoxia decreases the response to radiation treatment (13). The effect of tumour hypoxia on the response to radiation therapy is relevant to the management of rectal cancer.

Hypoxia-inducible factor $1 \alpha(\mathrm{HIF}-1 \alpha)$ is a protein involved in the cellular response to hypoxia centrally. It activates a variety of downstream genes involved in anaerobic metabolism and angiogenesis (14-16). These downstream gene protein products, which include VEGF, stromal cell-derived factor $1 \alpha$ (SDF-1 $\alpha)$ and PIGF, promote cell survival under hypoxic conditions. Among patients with colorectal cancer, expression of these $4 \mathrm{AMs}$ has been shown to correlate with rates of lymph node or liver metastasis, disease-free survival, and overall survival (17-20). However, the effects of pre-operative treatment on expression of AMs in rectal cancer remain unclear. The 4 AMs chosen for this study include HIF- $1 \alpha$, VEGF, SDF- $1 \alpha$ and PIGF.

The aims of this exploratory study were to a) characterise expression of AMs in LARC before NCRT, b) investigate the change in AM expression after NCRT and c) evaluate the relationship between AM expression and tumour response.

\section{Patients and methods}

Patients and neoadjuvant chemoradiotherapy regimen. Between March 2005 and August 2009 at Soonchunhyang University Hospital, a total of 55 patients with non-metastatic, locally advanced (radiological T3-T4 or $\mathrm{N}^{+}$and/or clinically bulky) and biopsy-proven primary rectal cancer received NCRT. The whole pelvic field received 25 fractions of $180 \mathrm{cGy} / \mathrm{day}$ over 5 weeks, for a total of 4,500-5,040 cGy, using a four-field box technique. Chemotherapy was administered intravenously and consisted of 5-fluorouracil (5-FU; $425 \mathrm{mg} / \mathrm{m}^{2} /$ day $)$ and leucovorin $\left(20 \mathrm{mg} / \mathrm{m}^{2} /\right.$ day $)$ during the first and fifth weeks of radiotherapy. Surgical resection at 6-8 weeks was performed following the completion of NCRT. All data were collected and recorded prospectively, and the clinical and pathological features were reviewed retrospectively. The patients were classified according to the $6^{\text {th }}$ edition of the American Joint Committee on Cancer staging system (21). Surgical specimens were evaluated for histopathologic staging as well as for pathologic response to NCRT. The detailed characteristics of the patients are listed in Table I. Our study was approved by the Clinical Ethics Review Committee of the Soonchunhyang University Hospital, Cheonan, Republic of Korea. Clinical consent was obtained from all patients.

Tissue microarray (TMA) construction. Areas representative of cancer were marked on haematoxylin and eosin-stained slides and TMAs were constructed. TMAs were created from formalin-fixed by $10 \%$ neutral buffered formalin, paraffinembedded tissues using a 2-mm-diameter punch (Unitma;
Unitech Science, Seoul, Korea). TMA blocks were assembled by obtaining duplicate cores from one patient block and re-embedding the two cores in an arrayed recipient block (Unitma; Unitech Science). A TMA block contains 60 cores from 30 samples.

Tumour response. Clinical stage was performed by an independent review conducted by a radiologist, and pathologic stage was reviewed by two independent pathologists. Downstaging was defined as staging reduction from pre-treatment stage (cStage) to pathologic stage (ypStage) (i.e. cIII to ypII, ypI or yp0; cII to ypI or yp0). Pathologic response (tumour regression) to NCRT was semiquantitatively determined by the amount of viable tumour versus the amount of fibrosis, ranging from no evidence of any NCRT effect to a complete response with no viable tumour identified, as described by Dworak et al (22). The following were characteristics of each grade: grade 0 , no regression; grade 1 , minor regression (dominant tumour mass with obvious fibrosis in $25 \%$ or less of the tumour mass); grade 2, moderate regression (dominant tumour mass with obvious fibrosis in $26-50 \%$ of the tumour mass); grade 3, good regression (dominant fibrosis outgrowing the tumour mass; i.e. $>50 \%$ tumour regression); and grade 4 , total regression (no viable tumour cells, only fibrotic mass). Patients with tumour regression grade (TRG) of 3 or 4 were considered as the responder group in our study.

Immunohistochemical (IHC) staining. The TMAs were sectioned at $4-\mu \mathrm{m}$ intervals, deparaffinised three times in xylene for $30 \mathrm{~min}$ and rehydrated with graded alcohols $(100 \%$ ethyl alcohol for $5 \mathrm{~min}$, 95\% ethyl alcohol for $3 \mathrm{~min}$ and $75 \%$ ethyl alcohol for $3 \mathrm{~min}$ ) and then heated in antigen retrieval solution (sodium citrate, $\mathrm{pH}$ 6.0) in a microwave for $20 \mathrm{~min}$. Sections were incubated in $\mathrm{H}_{2} \mathrm{O}_{2}$ for $10 \mathrm{~min}$ at room temperature. Furthermore, the sections were incubated with $150 \mathrm{ml}$ of the primary antibodies, VEGF (1:200; Millipore, USA), PIGF (1:200; R\&D system, USA), HIF-1 $\alpha$ (1:50; Proteintech, USA) and SDF-1 $\alpha$ (1:100; Novus Biologicals, USA) at $4^{\circ} \mathrm{C}$ overnight. Subsequently, the sections were washed in PBS buffer three times for $3 \mathrm{~min}$, treated with $150 \mathrm{ml}$ secondary antibody for $1 \mathrm{~h}$ at room temperature and stained with DAB solution (Dako, USA). The sections were then washed in PBS buffer for $10 \mathrm{~min}$. Finally, the sections were counterstained with hematoxylin for 3 min at room temperature, washed in distilled water 3 times for 3 min and mounted with coverslips.

IHC analysis. The VEGF, PIGF, HIF- $1 \alpha$ and SDF-1 $\alpha$ stained tissue cores were examined by 2 independent pathologists and a consensus score was determined for each specimen. A positive reaction for both antibodies was scored into 4 grades, according to the intensity of the staining: $0,1+, 2+$ and $3+$. The percentages of positive cells were also scored into 4 categories: $0(0 \%), 1(1-33 \%), 2(34-66 \%)$, and $3(67-100 \%)$. The final score, calculated as the product of the intensity score multiplied by the percentage score, was classified as follows: 0 for negative; 1-3 for weak; 4-6 for moderate; and 7-9 for strong.

Statistical analysis. The correlations between expression levels of hypoxia-related proteins and pathologic response to NCRT were evaluated by the $\chi^{2}$ or Fisher's exact test. The univariate 


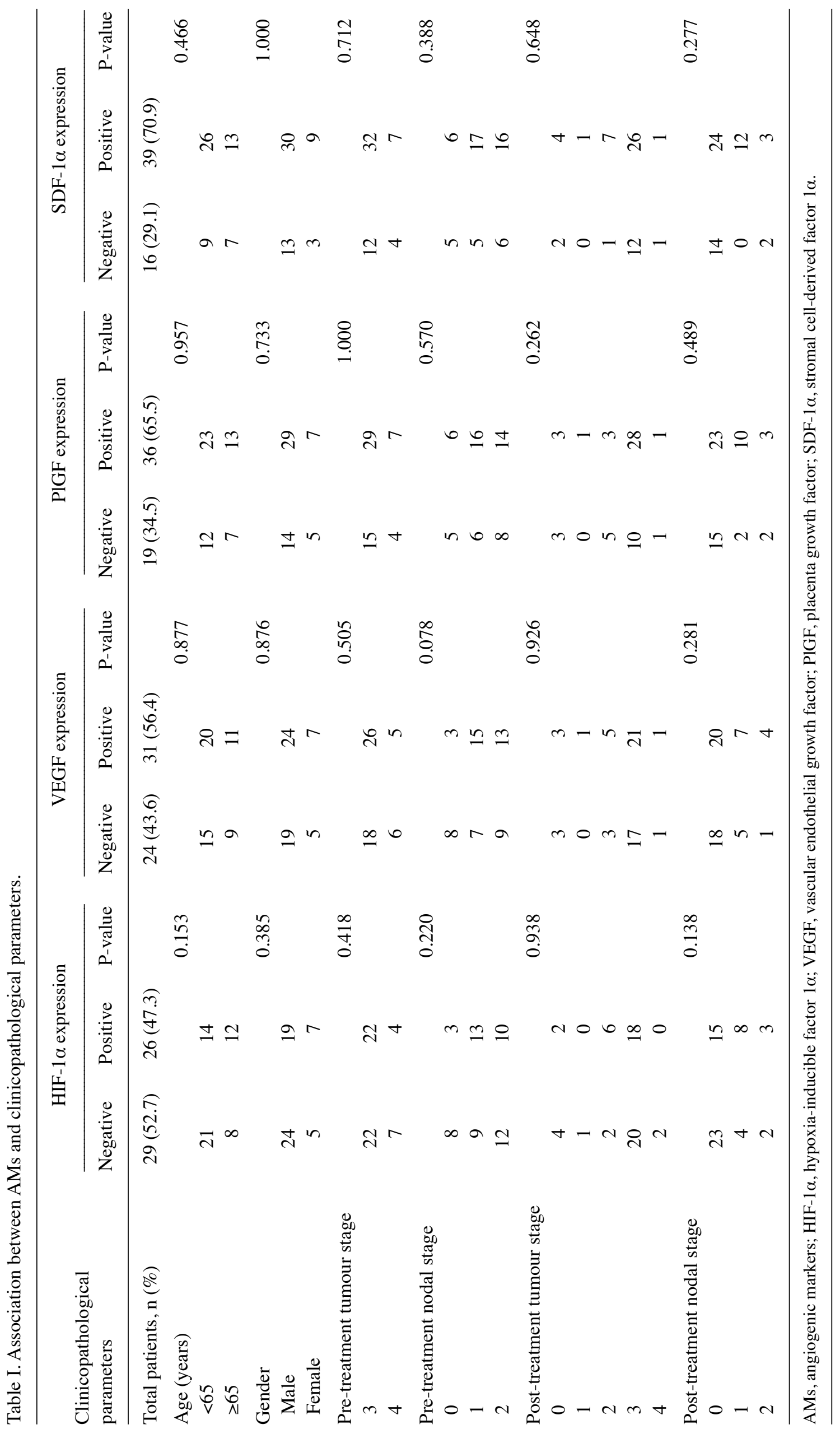


A

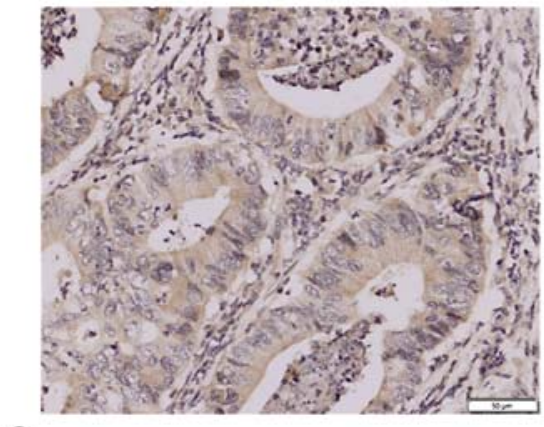

$\mathrm{C}$

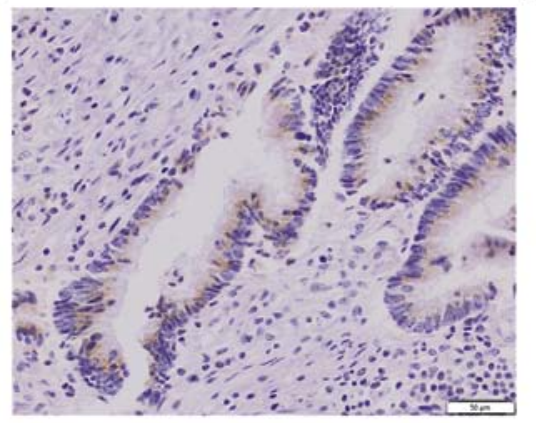

B

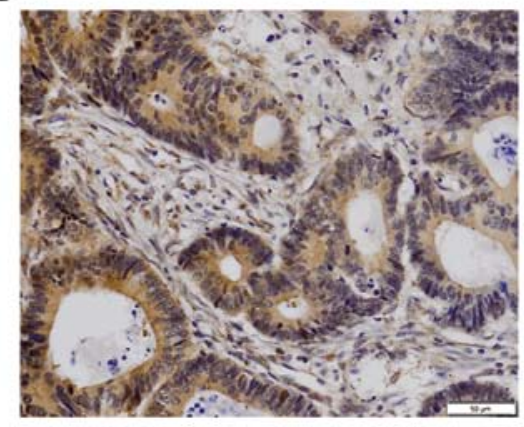

D

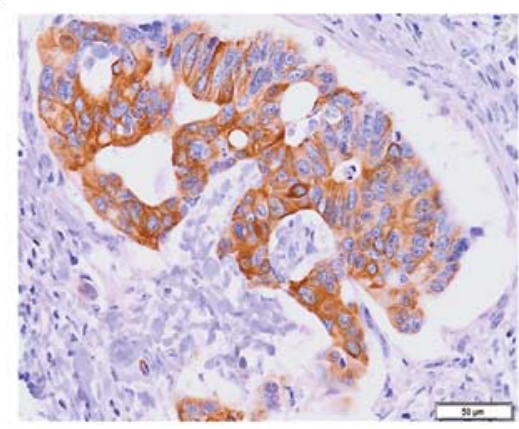

Figure 1. Immunoreactivity in the immunostained rectal carcinoma samples. (A) VEGF was weakly expressed in the cytoplasm. (B) HIF-1 $\alpha$ was moderately expressed in the cytoplasm and nuclei. (C) PIGF was weakly expressed in the cytoplasm. (D) SDF-1 $\alpha$ was strongly expressed in the cytoplasm and cytoplasmic membrane (magnification, $\mathrm{x} 400$ ). Scale bar, $50 \mu \mathrm{m}$.

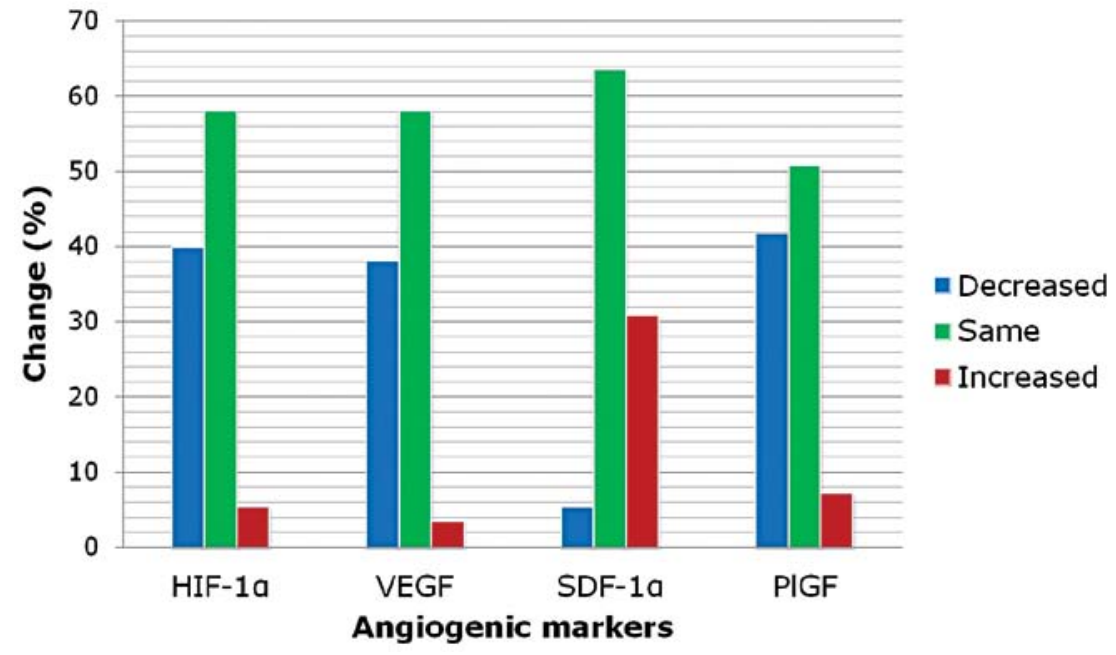

Figure 2. Change in staining status after neoadjuvant chemoradiation (NCRT). Expression of VEGF, PIGF and HIF-1 $\alpha$ protein was downregulated after NCRT $(\mathrm{P}<0.001, \mathrm{P}=0.001$ and $\mathrm{P}=0.044$, respectively $)$. However, SDF-1 $\alpha$ was upregulated after NCRT $(\mathrm{P}<0.001)$.

and multivariate analyses between response to NCRT and clinical or histopathologic parameters were performed by binary logistic regression model. All P-values quoted were two-sided, and $\mathrm{P}<0.05$ was considered to indicate a statistically significant difference. All the analyses were performed using SPSS v. 17.0 (SPSS, Inc., Chicago, IL, USA).

\section{Results}

Association between AM expression and clinicopathological variables. The mean age of the 55 patients with LARC was 56 years (range, $18-82$ years). In regards to gender, 43 (78.2\%) were male, and $12(21.8 \%)$ were female. Regarding the stage of disease, $11(20.0 \%)$ were at stage II, and $44(80.0 \%)$ were at stage III. Concerning the T stage, $44(80.0 \%)$ were T3 and $11(20.0 \%)$ were T4. The number of negative lymph node metastases was 11 (20.0\%); N1 was $22(40.0 \%)$, and $\mathrm{N} 2$ was $22(40.0 \%)$. A pCR was obtained in $9.1 \%$ cases (5 patients). Patient characteristics are summarised in Table I. As shown in Table I, expression levels of AMs were not statistically correlated to the clincopathological variables.

Change in AM expression in LARC before NCRT and after surgery. The positive expression rate of HIF-1 $\alpha$, VEGF, PIGF 


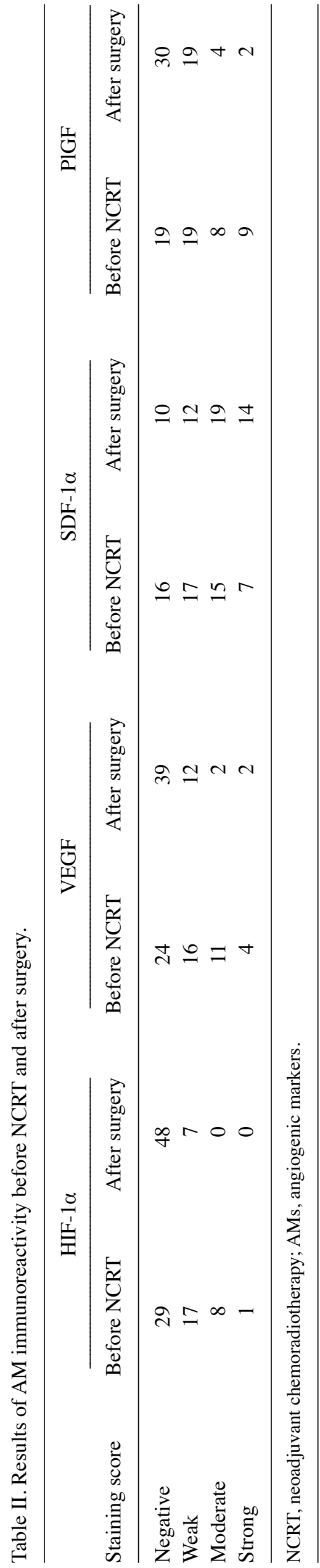

Table III. Association between tumour response and clinicopathological parameters.

\begin{tabular}{|c|c|c|c|}
\hline \multirow{2}{*}{$\begin{array}{l}\text { Clinicopathological } \\
\text { parameters }\end{array}$} & \multicolumn{2}{|c|}{ Tumour response } & \multirow[b]{2}{*}{ P-value } \\
\hline & $\mathrm{R}$ & NR & \\
\hline Age (years) & & & 0.877 \\
\hline$<65$ & 20 & 15 & \\
\hline$\geq 65$ & 11 & 9 & \\
\hline Gender & & & 0.416 \\
\hline Male & 23 & 20 & \\
\hline Female & 8 & 4 & \\
\hline Pre-treatment tumour stage & & & 0.180 \\
\hline 3 & 27 & 17 & \\
\hline 4 & 4 & 7 & \\
\hline Pre-treatment nodal stage & & & 0.517 \\
\hline 0 & 4 & 7 & \\
\hline 1 & 15 & 7 & \\
\hline 2 & 12 & 10 & \\
\hline Pre-treatment VEGF staining & & & 0.773 \\
\hline Negative & 13 & 11 & \\
\hline Positive & 18 & 13 & \\
\hline Pre-treatment PlGF staining & & & 0.190 \\
\hline Negative & 13 & 6 & \\
\hline Positive & 18 & 18 & \\
\hline Pre-treatment SDF-1 $\alpha$ staining & & & 0.235 \\
\hline Negative & 11 & 5 & \\
\hline Positive & 20 & 19 & \\
\hline Pre-treatment HIF- $1 \alpha$ staining & & & 0.368 \\
\hline Negative & 18 & 11 & \\
\hline Positive & 13 & 13 & \\
\hline Post-treatment VEGF staining & & & 0.074 \\
\hline Negative & 19 & 20 & \\
\hline Positive & 12 & 4 & \\
\hline Post-treatment PIGF staining & & & 0.001 \\
\hline Negative & 23 & 7 & \\
\hline Positive & 8 & 17 & \\
\hline Post-treatment SDF- $1 \alpha$ staining & & & 0.159 \\
\hline Negative & 8 & 2 & \\
\hline Positive & 23 & 22 & \\
\hline Post-treatment HIF-1 $\alpha$ staining & & & 0.686 \\
\hline Negative & 28 & 20 & \\
\hline Positive & 3 & 4 & \\
\hline \multicolumn{4}{|l|}{ Change of staining status } \\
\hline VEGF & & & 0.400 \\
\hline Decreased & 10 & 11 & \\
\hline Same & 20 & 12 & \\
\hline Increased & 1 & 1 & \\
\hline PlGF & & & 0.568 \\
\hline Decreased & 12 & 11 & \\
\hline Same & 19 & 9 & \\
\hline Increased & 0 & 4 & \\
\hline
\end{tabular}


Table III. Continued.

\begin{tabular}{|c|c|c|c|}
\hline \multirow{2}{*}{$\begin{array}{l}\text { Clinicopathological } \\
\text { parameters }\end{array}$} & \multicolumn{2}{|c|}{ Tumour response } & \multirow[b]{2}{*}{$\mathrm{P}$-value } \\
\hline & $\mathrm{R}$ & NR & \\
\hline SDF-1 $1 \alpha$ & & & 0.016 \\
\hline Decreased & 3 & 0 & \\
\hline Same & 22 & 13 & \\
\hline Increased & 6 & 11 & \\
\hline HIF- $1 \alpha$ & & & 0.343 \\
\hline Decreased & 11 & 11 & \\
\hline Same & 19 & 13 & \\
\hline Increased & 1 & 0 & \\
\hline
\end{tabular}

R, responder; NR, non-responder.

and SDF-1 $\alpha$ was $47.3 \%$ (26/55), 56.4\% (31/55), $65.5 \%$ (36/55) and $70.9 \%$ (39/55) before NCRT, respectively. Weak, moderate and strong staining intensity of AMs is illustrated in Fig. 1. The expression rate of HIF- $1 \alpha$, VEGF, SDF- $1 \alpha$ and PIGF was increased by $1.8 \%(1 / 55), 3.6 \%(2 / 55), 30.9 \%(17 / 55)$ and $7.3 \%(4 / 55)$ after NCRT, respectively. Expression of VEGF, PIGF and HIF-1 $\alpha$ protein was downregulated after NCRT in the rectal cancer tissues $(\mathrm{P}<0.001, \mathrm{P}=0.001$ and $\mathrm{P}=0.044$, respectively). However, SDF-1 $\alpha$ was upregulated after NCRT (P<0.001; Table II, Fig. 2).

Relationship between tumour response to NCRT and clinicopathological variables. Upregulated expression of SDF-1a $(\mathrm{P}<0.016)$ and positive $\mathrm{PlGF}$ staining $(\mathrm{P}=0.001)$ after NCRT were significantly associated with resistance to NCRT. However, other clinicopathologic variables showed no correlation with tumour response (Table III). In multivariate analyses, positive PIGF staining after NCRT was found to be associated with resistance to NCRT [P=0.013; OR=0.197, 95\% confidence interval (CI), 0.055-0.705]. Only low pre-treatment tumour lymph node staging was associated with $\mathrm{pCR}(\mathrm{P}=0.002$; Table IV).

Relationship with AM expression. Before NCRT, an association was identified between HIF-1 $\alpha$ expression and SDF-1 $\alpha$ $(\mathrm{P}=0.034)$. HIF-1 $\alpha$ was not correlated with VEGF and PIGF. However, SDF-1 $\alpha$ had an association with PIGF $(\mathrm{P}=0.005)$. After surgery, HIF-1 $\alpha$ expression was not correlated with SDF-1 $\alpha(\mathrm{P}=0.621)$, and SDF-1 $\alpha$ tended to be associated with $\operatorname{PIGF}(\mathrm{P}=0.052)$.

\section{Discussion}

Recently, studies have attempted to identify predictive biomarkers, yet various studies only compared pre-treatment and post-treatment changes in biomarker expression (5). In this study, we investigated the predictive relevance of AM expression both in pre-treatment biopsies and in corresponding surgical specimens of 55 patients with LARC treated with standadised 5-FU-based NCRT. Comparing pre-treatment biopsies and surgical specimens, we observed a downregulation of
Table IV. Association between pCR and clinicopathological parameters.

\begin{tabular}{ll}
\hline & \multicolumn{2}{c}{$\mathrm{pCR}$} \\
\cline { 2 - 2 } $\begin{array}{l}\text { Clinicopathological } \\
\text { parameters }\end{array}$ & $(-)$ \\
\hline Age (years) & \\
$<65$ & 32 \\
$\geq 65$ & 18 \\
Gender & \\
Male & \\
Female & 40
\end{tabular}

Pre-treatment tumour stage

3

4

$39 \quad 5$

110

Pre-treatment nodal stage

0

1

2

(+) P-value

1.000

3

2

0.298

0.571

Pre-treatment VEGF staining

Negative

Positive

Pre-treatment PlGF staining

Negative

Positive

Pre-treatment SDF-1 $\alpha$ staining

Negative

Positive

Pre-treatment HIF-1 $\alpha$ staining

Negative

Positive

Post-treatment VEGF staining

Negative

Positive

Post-treatment PIGF staining

Negative

Positive

0.002

$\begin{array}{ll}7 & 4\end{array}$

$21 \quad 1$

220

$21 \quad 3$

$29 \quad 2$

$16 \quad 3$

$34 \quad 2$

0.622

$14 \quad 2$

$36 \quad 3$

0.355

$25 \quad 4$

$25 \quad 1$

1.000

35

15

0.056

25

25

0.220

Post-treatment SDF- $1 \alpha$ staining

Negative

Positive

$\begin{array}{ll}8 & 2\end{array}$

423

Post-treatment HIF-1 $\alpha$ staining

Negative

Positive

$43 \quad 5$

70

1.000

Change of staining status

VEGF

0.817

$\begin{array}{lrr}\text { Decreased } & 19 & 2 \\ \text { Same } & 29 & 3 \\ \text { Increased } & 2 & 0\end{array}$

PIGF

Decreased

0.835

Same

$21 \quad 2$

Increased 
Table IV. Continued.

\begin{tabular}{lrrr}
\hline & \multicolumn{2}{c}{ pCR } & \\
\cline { 2 - 3 } $\begin{array}{l}\text { Clinicopathological } \\
\text { parameters }\end{array}$ & $(-)$ & $(+)$ & P-value \\
\hline SDF-1 $\alpha$ & 2 & 1 & 0.053 \\
$\quad$ Decreased & 31 & 4 & \\
Same & 17 & 0 & \\
Increased & & & 0.418 \\
HIF-1 $\alpha$ & 21 & 1 & \\
$\quad$ Decreased & 28 & 4 & \\
Same & 1 & 0 & \\
Increased & & & \\
\hline
\end{tabular}

pCR, pathologic complete response.

VEGF, PIGF and HIF-1 $\alpha$. However, SDF-1 $\alpha$ was upregulated after NCRT. In addition, upregulated SDF-1 $\alpha$ after NCRT was significantly associated with resistance to NCRT. Our findings suggest that SDF- $1 \alpha$ is one of the important targets for resistance to NCRT and this finding is significant.

SDF-1 $\alpha$, also known as chemokine ligand 12 (CXCL12), and its receptor CXCR4, play important roles in the onset and progression of primary or metastatic cancer from various organs (23-26). In colorectal cancer (CRC), elevated SDF-1 $\alpha$ expression is associated with metastasis and poor prognosis $(27,28)$. In our investigation, upregulation of SDF-1 $\alpha$ in surgical specimens was related to resistance to NCRT. Thus, SDF- $1 \alpha$ appears to be a predictive marker to chemoradiation treatment. In an in vitro study using a CRC cell line, the results indicate that CXCR4 antagonistic therapy might prevent tumour cell dissemination and metastasis in CRC patients, consequently improving survival (29). Therefore, the targeting of SDF-1 $\alpha$ represents an attractive adjuvant treatment to eradicate cancer cells and induce anti-angiogenic effects in highly hypoxic tumours. Further study evaluating the distinctive value of SDF-1 $\alpha$ expression in LARC patients receiving NCRT is warranted. However, we did not observe a relationship between expression of AMs before NCRT and tumour reponse. Therefore, it is not possible to choose the 'right' patients who may require additional therapeutics (such as anti-angiogenesis), except NCRT, by analhysis of the specimen before treatment. These findings are difficult for clinical application.

We also found that positive expression of PlGF after NCRT was correlated with resistance to NCRT in multivariate analyses. PIGF is a cytokine in the VEGF family of growth factors, with 53\% homology to VEGF (30). It primarily regulates the angiogenic switch under pathologic states (31). PIGF recruits smooth muscle precursors that envelop developing vessels in tumours and together with VEGF produces more stable and mature vessels. PlGF may also facilitate metastasis by increasing the motility and invasion of malignant cells (32). Tumour overexpression of PIGF and VEGF together is associated with increased tumour angiogenesis and cancer growth $(33,34)$. However, in general, there was no correlation between elevated VEGF expression and survival $(35,36)$. Our results suggest that PIGF, than VEGF, is also an important target for resistance to NCRT. It would be worthwhile to determine whether or not PIGF is a predictive biomarker for patients with LARC receiving NCRT.

As shown in this study, an association was identified between HIF-1 $\alpha$ and SDF-1 $\alpha(\mathrm{P}=0.034)$. HIF- $1 \alpha$ was not correlated with VEGF and PIGF. However, SDF-1 $\alpha$ had an association with PIGF $(\mathrm{P}=0.005)$. Although HIF-1 $\alpha$ expression is known to drive expression of downstream proteins, differences in individual protein half-lives may not allow for a direct relationship between HIF-1 $\alpha$ and other proteins (37). Downstream proteins may have been influenced by other signaling pathways independent of HIF- $1 \alpha$, making their expression levels somewhat variable in relation to HIF-1 $\alpha$. The limited sample size and the heterogeneity of intratumoural oxygenation may also be responsible for these findings.

In summary, SDF-1 $\alpha$ and PlGF are relevant for resistance to NCRT. By comparison of pre-therapeutic and post-therapeutic intratumoural SDF- $1 \alpha$ and PlGF, our results suggest that therapeutic strategies to downregulate expression of SDF- $1 \alpha$ and PIGF during pre-operative treatment or to inhibit SDF-1 $\alpha /$ PIGF mediated signaling pathways may further increase the individual tumour response and, as a consequence, improve patient prognosis. Based on our results, patients with increased expression of SDF-1 $\alpha$ or positive expression of PIGF after NCRT might benefit from additional anti-SDF-1 $\alpha /$ PlGF therapeutics.

\section{Acknowledgements}

The authors would like to thank Kim Hyung-Joo and Park So-Young for providing excellent technical assistance.

\section{References}

1. Siegel R, Naishadham D and Jemal A: Cancer statistics, 2012. CA Cancer J Clin 62: 10-29, 2012.

2. Sauer R, Becker H, Hohenberger W, Rodel C, Wittekind C, Fietkau R, Martus P, Tschmelitsch J, Hager E, Hess CF, Karstens JH, Liersch T, Schmidberger H, Raab R and German Rectal Cancer Study Group: Preoperative versus postoperative chemoradiotherapy for rectal cancer. N Engl J Med 351: 1731-1740, 2004.

3. Roh MS, Colangelo LH, O'Connell MJ, Yothers G, Deutsch M Allegra CJ, Kahlenberg MS, Baez-Diaz L, Ursiny CS, Petrelli NJ and Wolmark N: Preoperative multimodality therapy improves disease-free survival in patients with carcinoma of the rectum: NSABP R-03. J Clin Oncol 27: 5124-5130, 2009.

4. Maas M, Nelemans PJ, Valentini V, Das P, Rödel C, Kuo LJ, Calvo FA, García-Aguilar J, Glynne-Jones R, Haustermans K, Mohiuddin M, Pucciarelli S, Small W Jr, Suárez J, Theodoropoulos G, Biondo S, Beets-Tan RG and Beets GL: Long-term outcome in patients with a pathological complete response after chemoradiation for rectal cancer: a pooled analysis of individual patient data. Lancet Oncol 11: 835-844, 2010.

5. Sprenger T, Rödel F, Beissbarth T, Conradi LC, Rothe H, Homayounfar K, Wolff HA, Ghadimi BM, Yildirim M, Becker H, Rödel C and Liersch T: Failure of downregulation of survivin following neoadjuvant radiochemotherapy in rectal cancer is associated with distant metastases and shortened survival. Clin Cancer Res 17: 1623-1631, 2011.

6. Edden Y, Wexner SD and Berho M: The use of molecular markers as a method to predict the response to neoadjuvant therapy for advanced stage rectal adenocarcinoma. Colorectal Dis 14: 555-561, 2012.

7. Trakarnsanga A, Ithimakin S and Weiser MR: Treatment of locally advanced rectal cancer: controversies and questions. World J Gastroenterol 18: 5521-5532, 2012. 
8. Chin KF, Greenman J, Gardiner E, Kumar H, Topping K and Monson J: Pre-operative serum vascular endothelial growth factor can select patients for adjuvant treatment after curative resection in colorectal cancer. Br J Cancer 83: 1425-1431, 2000.

9. Cascinu S, Graziano F, Catalano V, Staccioli MP, Rossi MC Baldelli AM, Barni S, Brenna A, Secondino S, Muretto P and Catalano G: An analysis of p53, BAX and vascular endothelial growth factor expression in node-positive rectal cancer. Relationships with tumour recurrence and event-free survival of patients treated with adjuvant chemoradiation. Br J Cancer 86: 744-749, 2002

10. Willett CG, Duda DG, di Tomaso E, Boucher Y, Ancukiewicz M, Sahani DV, Lahdenranta J, Chung DC, Fischman AJ, Lauwers GY, Shellito P, Czito BG, Wong TZ, Paulson E, Poleski M, Vujaskovic Z, Bentley R, Chen HX, Clark JW and Jain RK: Efficacy, safety, and biomarkers of neoadjuvant bevacizumab, radiation therapy, and fluorouracil in rectal cancer: a multidisciplinary phase II study. J Clin Oncol 27: 3020-3026, 2009.

11. Brizel DM, Scully SP, Harrelson JM, Layfield LJ, Bean JM, Prosnitz LR and Dewhirst MW: Tumor oxygenation predicts for the likelihood of distant metastases in human soft tissue sarcoma. Cancer Res 56: 941-943, 1996.

12. Nordsmark M, Alsner J, Keller J, Nielsen OS, Jensen OM, Horsman MR and Overgaard J: Hypoxia in human soft tissue sarcomas: adverse impact on survival and no association with p53 mutations. Br J Cancer 84: 1070-1075, 2001

13. Koukourakis MI, Bentzen SM, Giatromanolaki A, Wilson GD, Daley FM, Saunders MI, Dische S, Sivridis E and Harris AL: Endogenous markers of two separate hypoxia response pathways (hypoxia inducible factor 2 alpha and carbonic anhydrase 9) are associated with radiotherapy failure in head and neck cancer patients recruited in the CHART randomized trial. J Clin Oncol 24: 727-735, 2006.

14. Sowter HM, Ratcliffe PJ, Watson P, Greenberg AH and Harris AL: HIF-1-dependent regulation of hypoxic induction of the cell death factors BNIP3 and NIX in human tumors. Cancer Res 61: 6669-6673, 2001.

15. Lal A, Peters H, St Croix B, Haroon ZA, Dewhirst MW, Strausberg RL, Kaanders JH, van der Kogel AJ and Riggins GJ: Transcriptional response to hypoxia in human tumors. J Natl Cancer Inst 93: 1337-1343, 2001.

16. Zhong H, De Marzo AM, Laughner E, Lim M, Hilton DA, Zagzag D, Buechler P, Isaacs WB, Semenza GL and Simons JW: Overexpression of hypoxia-inducible factor 1 alpha in common human cancers and their metastases. Cancer Res 59: 5830-5835, 1999.

17. Ishigami SI, Arii S, Furutani M, Niwano M, Harada T, Mizumoto M, Mori A, Onodera $\mathrm{H}$ and Imamura M: Predictive value of vascular endothelial growth factor (VEGF) in metastasis and prognosis of human colorectal cancer. Br J Cancer 78 : 1379-1384, 1998

18. Rajaganeshan R, Prasad R, Guillou PJ, Poston G, Scott N and Jayne DG: The role of hypoxia in recurrence following resection of Dukes' B colorectal cancer. Int J Colorectal Dis 23: 1049-1055, 2008.

19. Wei SC, Liang JT, Tsao PN, Hsieh FJ, Yu SC and Wong JM: Preoperative serum placenta growth factor level is a prognostic biomarker in colorectal cancer. Dis Colon Rectum 52: 1630-1636, 2009.

20. Saigusa S, Toiyama Y, Tanaka K, Yokoe T, Okugawa Y, Fujikawa H, Matsusita K, Kawamura M, Inoue Y, Miki C and Kusunoki M: Cancer-associated fibroblasts correlate with poor prognosis in rectal cancer after chemoradiotherapy. Int J Oncol 38: 655-663, 2011

21. Greene FL, Page DL, Fleming ID, Fritz AG, Balch CM and Haller DG (eds): AJCC Cancer Staging Handbook - TNM Classification of Malignant Tumors. 6th edition. Springer-Verlag, New York, 2002

22. Dworak O, Keilholz L and Hoffmann A: Pathological features of rectal cancer after preoperative radiochemotherapy. Int $\mathbf{J}$ Colorectal Dis 12: 19-23, 1997.

23. Müller A, Homey B, Soto H, Ge N, Catron D, Buchanan ME, McClanahan T, Murphy E, Yuan W, Wagner SN, Barrera JL, Mohar A, Verastegui E and Zlotnik A: Involvement of chemokine receptors in breast cancer metastasis. Nature 410: 50-56, 2001.
24. Orimo A, Gupta PB, Sgroi DC, Arenzana-Seisdedos F, Delaunay T, Naeem R, Carey VJ, Richardson AL and Weinberg RA: Stromal fibroblasts present in invasive human breast carcinomas promote tumor growth and angiogenesis through elevated SDF-1/CXCL12 secretion. Cell 121: 335-348, 2005.

25. Schrader AJ, Lechner O, Templin M, Dittmar KE, Machtens S, Mengel M, Probst-Kepper M, Franzke A, Wollensak T, Gatzlaff P, Atzpodien J, Buer J and Lauber J: CXCR4/CXCL12 expression and signalling in kidney cancer. Br J Cancer 86: 1250-1256, 2002.

26. Taichman RS, Cooper C, Keller ET, Pienta KJ, Taichman NS and McCauley LK: Use of the stromal cell-derived factor-1/CXCR4 pathway in prostate cancer metastasis to bone. Cancer Res 62: 1832-1837, 2002

27. Matsusue R, Kubo H, Hisamori S, Okoshi K, Takagi H, Hida K, Nakano K, Itami A, Kawada K, Nagayama S and Sakai Y: Hepatic stellate cells promote liver metastasis of colon cancer cells by the action of SDF-1/CXCR4 axis. Ann Surg Oncol 16: 2645-2653, 2009

28. Yoshitake N, Fukui H, Yamagishi H, Sekikawa A, Fujii S, Tomita S, Ichikawa K, Imura J, Hiraishi H and Fujimori T: Expression of SDF-1 alpha and nuclear CXCR4 predicts lymph node metastasis in colorectal cancer. Br J Cancer 98: 1682-1689, 2008.

29. Heckmann D, Laufs S, Maier P, Zucknick M, Giordano FA, Veldwijk MR, Eckstein V, Wenz F, Zeller WJ, Fruehauf S and Allgayer H: A Lentiviral CXCR4 overexpression and knockdown model in colorectal cancer cell lines reveals plerixafor-dependent suppression of SDF-1 $\alpha$-induced migration and invasion. Onkologie 34: 502-508, 2011.

30. Wei SC, Tsao PN, Yu SC, Shun CT, Tsai-Wu JJ, Wu CH, Su YN, Hsieh FJ and Wong JM: Placenta growth factor expression is correlated with survival of patients with colorectal cancer. Gut 54: 666-672, 2005.

31. Carmeliet P, Moons L, Luttun A, Vincenti V, Compernolle V, De Mol M, Wu Y, Bono F, Devy L, Beck H, Scholz D, Acker T, DiPalma T, Dewerchin M, Noel A, Stalmans I, Barra A, Blacher S, VandenDriessche T, Ponten A, Eriksson U, Plate KH, Foidart JM, Schaper W, Charnock-Jones DS, Hicklin DJ, Herbert JM, Collen D and Persico MG: Synergism between vascular endothelial growth factor and placental growth factor contributes to angiogenesis and plasma extravasation in pathological conditions. Nat Med 7: 575-583, 2001.

32. Fischer C, Jonckx B, Mazzone M, Zacchigna S, Loges S, Pattarini L, Chorianopoulos E, Liesenborghs L, Koch M, De Mol M, Autiero M, Wyns S, Plaisance S, Moons L, van Rooijen N, Giacca M, Stassen JM, Dewerchin M, Collen D and Carmeliet P: Anti-PIGF inhibits growth of VEGF(R)inhibitor-resistant tumors without affecting healthy vessels. Cell 131: 463-475, 2007.

33. Landriscina M, Cassano A, Ratto C, Longo R, Ippoliti M, Palazzotti B, Crucitti F and Barone C: Quantitative analysis of basic fibroblast growth factor and vascular endothelial growth factor in human colorectal cancer. Br J Cancer 78: 765-770, 1998.

34. Adini A, Kornaga T, Firoozbakht F and Benjamin LE: Placental growth factor is a survival factor for tumor endothelial cells and macrophages. Cancer Res 62: 2749-2752, 2002.

35. Lee JC, Chow NH, Wang ST and Huang SM: Prognostic value of vascular endothelial growth factor expression in colorectal cancer patients. Eur J Cancer 36: 748-753, 2000.

36. Khorana AA, Ryan CK, Cox C, Eberly S and Sahasrabudhe DM: Vascular endothelial growth factor, CD68, and epidermal growth factor receptor expression and survival in patients with stage II and stage III colon carcinoma: a role for the host response in prognosis. Cancer 97: 960-968, 2003.

37. Lee-Kong SA, Ruby JA, Chessin DB, Pucciarelli S, Shia J, Riedel ER, Nitti D and Guillem JG: Hypoxia-related proteins in patients with rectal cancer undergoing neoadjuvant combined modality therapy. Dis Colon Rectum 55: 990-995, 2012. 